94

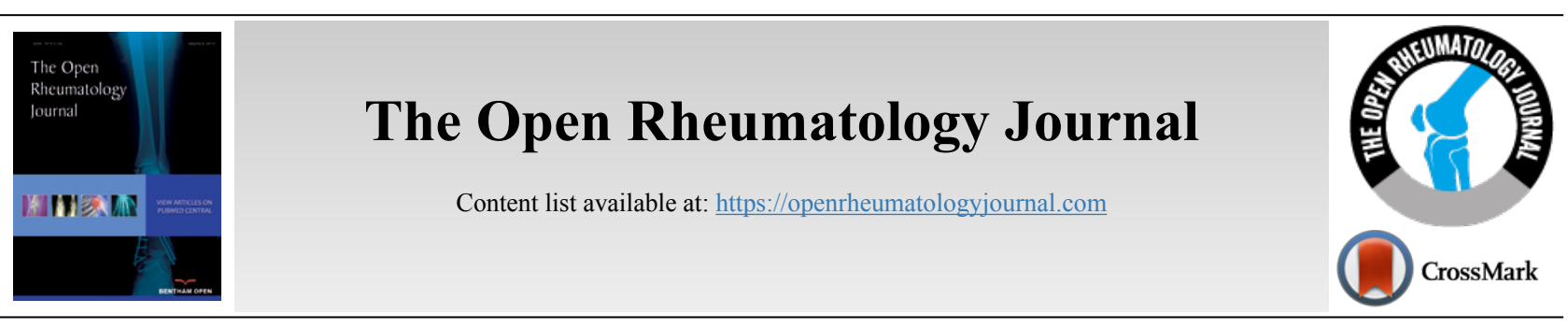

RESEARCH ARTICLE

\title{
Management and Comorbidities in Middle-European Patients with Rheumatoid Arthritis: A Retrospective, Cross-sectional Comparison with COMORA Data
}

\author{
Myroslav Levytskyi ${ }^{1}$, Sarah Maier ${ }^{1}$ and Michael Schirmer ${ }^{1, *} \mathbb{C}$ \\ ${ }^{1}$ Department of Internal Medicine, Medical University of Innsbruck, Innsbruck, Austria
}

\begin{abstract}
:
Objective:

To assess disease-specific characteristics and comorbidities in consecutive Middle-European Rheumatoid Arthritis (RA) patients, and to compare results with international data.

Methods:

Cross-sectional retrospective analysis of consecutive RA patients from a Middle-European outpatient service. Data are compared to those of the international "Co-morbidity in Rheumatoid Arthritis" (COMORA) cohort.

Results:

80 RA patients with mean disease duration of $10.6 \pm 8.3$ years were enrolled within 5 months. Age was $62 \pm 13$ years and $75 \%$ were female. The Middle-European cohort showed slightly lower disease activity than the Austrian COMORA subcohort. $88.8 \%$ of all Middle-European RA patients were in remission or had low disease activity. Despite comparable disease characteristics, the percentage of patients ever treated with biological disease-modifying antirheumatic drugs (bDMARDs) was lower in the middle-European cohort $(36.3 \%)$ than in the Austrian subcohort of COMORA (59\%), but similar to the international COMORA cohort (39\%). More smokers were in the Austrian COMORA subcohort (48.0) than in the Middle-European $(22.5 \%)$ and the COMORA cohort (13\%). Hypertension $(38.8 \%)$ and osteoporosis $(30.0 \%)$ were the most frequent comorbidities.

\section{Conclusion:}

Comparison of RA patients from this Middle-European cohort with the Austrian COMORA subcohort showed less frequent use of bDMARDs during disease course - probably according to the local referral structure. $88.8 \%$ of the Middle-European RA-patients achieved the treat-to targetaim of remission or low disease activity.
\end{abstract}

Keywords: Rheumatoid arthritis, Health care, Treatment , Comorbidity, Real-life,epidemiology, Management of patient.

\begin{tabular}{|l|l|l|r}
\hline Article History & Received: September 24, 2019 & Revised: December 06, 2019 & Accepted: December 24, 2019
\end{tabular}

\section{INTRODUCTION}

For Rheumatoid Arthritis (RA), mortality is increased by 1.5 -fold compared to the general population, mainly due to a higher incidence rates of Cardiovascular (CV) diseases, infections and neoplasms [1, 2]. As RA is chronic and affects about $0.5-1.0 \%$ of adults in Europe and the US, optimal management including search for CV risks is an organizational challenge [3]. There is increasing evidence for a possible role of nurses in the daily management of these patients [4], especially for patients in remission or with low disease activity.

* Address correspondence to this author at the Department of Internal Medicine, Medical University of Innsbruck, A-6020 Innsbruck Anichstrasse 35, Austria; Tel: 0043512504 81833; E-mail: michael.schirmer@i-med.ac.at
Despite improvement of RA management over the last decades, the burden of comorbidities still remains a significant problem. The "Co-morbidity in Rheumatoid Arthritis" (COMORA) study is the largest international cross-sectional study world-wide which evaluated disease activity, comorbidities and their management in 17 countries [5]. Comparisons of national cohorts with the COMORA cohort have been performed in Egypt, Korea and Spain [6 - 8], and authors proposed more awareness to screen and monitor comorbidities [6] and an increasing attention to $\mathrm{CV}$ risk and malignancies [7].

The aim of this study is to assess comorbidities in consecutive Middle-European (M-E) RA-patients and to 
compare data with those from the COMORA cohort [5].

\section{MATERIAL AND METHODS}

This cross-sectional analysis included 80 consecutive outpatients diagnosed with RA, who were routinely examined by one rheumatologist in a single secondary rather than tertiary-level M-E rheumatology service during September 27, 2017 and February 27, 2018. In this setting all visits are covered by the national security insurance system, thus guaranteeing free and equal access for all patients. Consecutive patients were included by a single investigator after informed and written consent (SolutionX project - approved by the local ethics committee (AN2017-0041 370/4.18). Pretreatment of recruited RA-patients was shared by all physicians of the unit.

In the hospital documentation system, complete charts are available since 2001. Documentation is not specifically structured for RA disease. After extensive chart review, patients' data were anonymized for statistical evaluations. Excel and SPSS version 23 were used. Normal distribution was assumed for a sample size larger than 30 , and the unpaired ttest and the chi-squared test were used as indicated.

For a comparison with international data, results from the international COMORA trial were used as published [5]. In the COMORA trial, data from 2 participating Eastern Austrian centers were included forming the Austrian subcohort, which both are well-established more for tertiary than secondary care.

\section{RESULTS}

Patients' demographics and disease characteristics are outlined in Table 1. Compared to the international COMORAcohort, M-E patients were older and showed a slightly lower disease activity.

Table 1. Characteristics of 80 consecutive MiddleEuropean RA-patients (in comparison with the Austrian COMORA subcohort of 204 RA patients and 3920 patients of the total international COMORA cohort). The chi ${ }^{2}$ test and unpaired t-tests were used for comparisons between Middle-European and COMORA cohorts.

\begin{tabular}{|c|c|c|c|}
\hline Patients' Characteristics & Middle-Europe & $\begin{array}{c}\text { COMORA } \\
\text { Austria }\end{array}$ & COMORA \\
\hline Gender (\% female) & 75.0 & 82.0 & 81.7 \\
\hline Age (mean years \pm SD) & $62 \pm 13$ & $59 \pm 13^{+}$ & $56 \pm 13^{* * *}$ \\
\hline $\begin{array}{c}\text { Duration of disease (mean } \\
\text { years } \pm \text { SD) }\end{array}$ & $10.6 \pm 8.5$ & $11 \pm 10$ & $9.6 \pm 8.7$ \\
\hline $\begin{array}{c}\text { Disease activity } \\
\text { (DAS28-ESR, mean } \pm \\
\text { SD), n (\%) }\end{array}$ & $2.5 \pm 1.1$ & $3.3 \pm 1.3^{* * * *}$ & $3.7 \pm 1.6^{* * *}$ \\
\hline
\end{tabular}

As also shown in Table 1, using CDAI $88.8 \%$ of the M-E patients were in remission or had a low disease activity. $62 \%$ of M-E patients tested seropositive, and $68.8 \%$ were ACPApositive, $8.9 \%$ showed a typical rheumatoid nodule; the mean erythrocyte sedimentation rate was $19.3 \pm 14.0 \mathrm{~mm} / \mathrm{h}$ and Creactive protein $0.7 \pm 1.6 \mathrm{mg} / \mathrm{dl}$ (data are not available for the COMORA cohort). In M-E, less patients had ever been treated with biological disease-modifying antirheumatic drugs (bDMARDs) compared to the Austrian COMORA subcohort ( $36.3 \%$ vs. $59 \%, \mathrm{p}<0.001$ ), but the percentage of M-E patients was comparable to that of the international COMORA cohort (Table 2). All M-E patients with TNF-inhibitors were cotreated with a conventional synthetic (cs)DMARD, the 2 patients without csDMARD-cotreatment received IL6-inhibitor or a JAK-inhibitor.

Table 2. Immunosuppressive and pain medication of Middle-European RA-patients to COMORA-data. Data are given in absolute numbers ( $\%$ in brackets).

bDMARD, biological disease-modifying antirheumatic drug (DMARD), csDMARD, conventional synthetic DMARD; MTX, methotrexate; n.a., not available; NSAIDs, non-steroidal antirheumatic drugs; $\mathbf{p}<\mathbf{0 . 0 1}$, highly significant (using chi $^{2}$-test for comparison with MiddleEuropean cohort).

\begin{tabular}{|c|c|c|c|}
\hline Medication & Middle-European & $\begin{array}{c}\text { COMORA } \\
\text { Austria }\end{array}$ & COMORA \\
\hline NSAIDs (\%) & $43(53.8)$ & $102(50)$ & $2156(55)$ \\
\hline Glucocorticoids (\%) & $23(28.8)$ & $65(32)$ & $2117(54)^{* * *}$ \\
\hline MTX (\%) & $75(93.8)$ & $192(94)$ & $3489(89)$ \\
\hline $\begin{array}{c}\text { bDMARDs (\% ever } \\
\text { treated) }\end{array}$ & $29(36.3)$ & $120(59)^{* * * *}$ & $1529(39)$ \\
\hline $\begin{array}{c}\text { - bDMARDs with } \\
\text { csDMARDs (\%) }\end{array}$ & $23(28.8)$ & n.a. & n.a. \\
\hline $\begin{array}{c}\text { - bDMARDs without } \\
\text { csDMARD (\%) }\end{array}$ & $2(2.5)$ & n.a. & n.a. \\
\hline $\begin{array}{c}\text { - TNF-inhibitor } \\
\text { without csDMARD } \\
(\%)\end{array}$ & $0(0)$ & n.a. & n.a. \\
\hline \multicolumn{2}{|l|}{} \\
\hline
\end{tabular}

Concerning the $\mathrm{CV}$ risk factors, smokers were less frequent in M-E than in the Austrian COMORA subcohort, but tended to be more frequent than in the international COMORA cohort (Table 3). Prevalence of arterial hypertension and diabetes mellitus as well as the percentage of patients treated with antihypertensive drugs did not significantly differ between the cohorts, but fewer M-E patients were treated with lipid lowering drugs compared to the Austrian COMORA subcohort (with $8.8 \%$ vs. $21 \%, \mathrm{p}<0.05$ ). In M-E, $12.5 \%$ of the patients were obese (data from the COMORA cohort are missing).

$\mathrm{CV}$ events, chronic obstructive pulmonary disease and neoplasms were rare and therefore not comparable between the cohorts. For osteoporosis, there was a high prevalence of $30 \%$ in the M-E patients, but data lack for the COMORA cohort. Supplementation of calcium was comparable between the M-E and the COMORA cohort (with $51.3 v s .44 \%$, respectively).

\section{DISCUSSION}

Assessment of management and comorbidities in RA compared to the international COMORA data can be considered as a quality effort, possibly revealing interesting aspects for future work.

First, in the M-E cohort, $88.8 \%$ of patients achieved the treat-to-target aim of remission or low disease activity. These patients are doing fine but still need monitoring and require rapid and timely access to care. Evidence for a possible role of nurses with specific training is growing, and detailed guidelines may help to manage these patients according to the updated EULAR recommendations in the future [4]. 
Table 3. Cardiovascular events and risk factors together with other comorbidities in RA-patients from the MiddleEuropean compared to the Austrian COMORA subcohort and the international COMORA cohort. Data are given in absolute numbers (with \% of all available data in brackets).

\begin{tabular}{|c|c|c|c|}
\hline $\begin{array}{c}\text { Risks and } \\
\text { Comorbidities }\end{array}$ & Middle-European & $\begin{array}{c}\text { COMORA } \\
\text { Austria }\end{array}$ & COMORA \\
\hline Cardiovascular events & $3(3.8)$ & $12(6)$ & $235(6)$ \\
\hline $\begin{array}{c}\text { Cardiovascular risk } \\
\text { factors }\end{array}$ & & & \\
\hline - Current smoker & $18(22.5)$ & $98(48)^{* * *}$ & $510(13)^{*}$ \\
\hline - Arterial hypertension & $31(38.8)$ & $106(52)^{+}$ & $1584(40.4)$ \\
\hline - Diabetes mellitus & $9(11.3)$ & $24(12)$ & $549(14.0)$ \\
\hline - Obesity & $10(12.5)$ & n.a. & n.a. \\
\hline COPD & $2(2.5)$ & $10(5)$ & $137(3.5)$ \\
\hline $\begin{array}{c}\text { Neoplasms with } \\
\text { malignity }\end{array}$ & & & \\
\hline - any solid tumor & $2(2.5)$ & n.a. & $176(4.5)$ \\
\hline - basocellular skin tumor & $0(0)$ & $6(3)$ & $78(2)$ \\
\hline
\end{tabular}

Second, in the M-E cohort, all patients treated with TNFinhibitors are co-treated with a csDMARD. This frequent use of csDMARDs in the M-E cohort is in contrast to other cohorts showing up to $30 \%$ of patients under TNF-inhibitors but without co-use of csDMARDs [9]. Due to a similar methodological approach, the patients' compliance should be comparable in the different cohorts. Patients' education and easy access to a nurse or physician in case of suspected sideeffects may be more important than usually believed. Interestingly, only $29 \%$ of the M-E patients were treated with GCs, far less than in the COMORA cohort (with 54\%) - despite similar use of NSAIDs, csDMARDs and bDMARDs.

Third, with $59 \%$, the use of bDMARDs was higher in the Austrian COMORA subcohort than in the M-E cohort with $36 \%$. This observation suggests a more active disease course in the Austrian subcohort, but it may also reflect different patients' recruitment from primary and secondary centers. Also, this finding could be related to the higher rate of current smokers in the Austrian COMORA subcohort (48\%) compared to the M-E cohort (23\%) and the general Austrian population (24.3\%) [10]. Whether this higher percentage of smoking explains the higher disease activity with the need for more intensive treatment with bDMARDs in the Austrian COMORA subcohort, remains open. Nevertheless, the 1.56-fold higher prevalence of smoking in RA [11], smoking as risk factor for the 1.5-fold increased CV events in RA [12], and the evidence for negative effects of smoking on TNF inhibitors' response in RA [13 - 15], strongly argues for advising all RA-patients to quit smoking.

Indeed, more $\mathrm{CV}$ risk factors make a contribution to the development of CV disease in RA, with arterial hypertension as the most prevalent one $[11,16]$. In the international COMORA cohort, the prevalence of hypertension was similar, but in the Austrian COMORA subcohort, arterial hypertension was more frequent than in the M-E cohort (40 vs. 52 vs. 39\%, respectively). As underlying causes, persistence of chronic inflammation, physical inactivity caused by pain, stiffness or permanent joint damage and the hypertension as potential adverse event of NSAIDs can be discussed. Data for other risk factors like diabetes mellitus, obesity and hyperlipidemia were comparable or not available. Concerning the use of lipidlowering agents [17], M-E patients use less lipid-lowering agents than the Austrian COMORA subcohort patients (9 vs. $21 \%$, respectively), whereas the difference between the M-E cohort and the COMORA patients (with 17\%) is not significant. With these risk factors in mind, in the M-E cohort, $\mathrm{CV}$ events are rare $(3.8 \%$ vs. $6 \%$ in the COMORA cohort), and appear comparable to data from the US-based CORRONA registry with a history of myocardial infarction in $3.7 \%$ [18] and the international QUEST-RA study with lifetime prevalence of $3.2 \%$ for myocardial infarction and $1.9 \%$ for stroke [19]. Therefore, smoking and other CV risk factors are recommended to be monitored at least every 5 years and after major changes of DMARD treatment [12].

Out of the non-CV comorbidities, osteoporosis is frequently diagnosed in the M-E cohort $(30 \%$ compared to $6.5 \%$ in the male and $22.2 \%$ in the female general population aged $>50$ years [20]. As diagnostic data of the COMORA cohort are not available, supplementation with Vitamin D and calcium was observed and showed similar use in the M-E compared to the COMORA cohort.

The advantage of the M-E cohort is that 80 out of 81 consecutive patients participated in the study. Comparable methodological approaches are available in registries, but registries not necessarily include all consecutive patients as a potential bias. Both the M-E cohort and the Austrian COMORA subcohort are Austrian cohorts. However, the M-E cohort is located in Western Austria with fewer rheumatologists, whereas the Austrian subcohort of the COMORA trial came from Eastern Austria with more rheumatologists serving for secondary care. Therefore, in the M-E cohort, more RA-patients are diagnosed and monitored who would not qualify for a universitary out-patient center in case of available alternative rheumatologists within the insurance plan as in Eastern Austria.

The main limitation of this study is its retrospective and unstructured design and that charts before 2001 are missing. Many data on blood pressure, blood glucose level and serum lipid levels are missing as these parameters are not routinely assessed in this outpatient clinic. Due to the limited number of 80 patients, the prevalence of rarer comorbidities like COPD and neoplasms could not be compared to the COMORA data. Routinely using CV risk scores would allow direct comparison of $\mathrm{CV}$ risk with the COMORA cohort.

\section{CONCLUSION}

Taken together, the comparison of RA patients from this Middle-European cohort with the Austrian COMORA subcohort showed less frequent use of bDMARDs during disease course, possibly related to the markedly lower smoking status. Most comorbidities were comparable with the COMORA cohort, but assessment in clinical routine can be improved. $88.8 \%$ of the Middle-European RA-patients achieved the treat-to target-aim of remission or low disease activity. 


\section{ETHICS APPROVAL AND CONSENT TO PARTI- CIPATE}

Ethical vote was obtained from the ethical commission of the Innsbruck Medical University (AN2017-0041 370/4.18).

\section{HUMAN AND ANIMAL RIGHTS}

Not applicable.

\section{CONSENT FOR PUBLICATION}

Informed and written consent was obtained by all patients.

\section{AVAILABILITY OF DATA AND MATERIALS}

Not applicable.

\section{FUNDING}

None.

\section{CONFLICT OF INTEREST}

The author declares no conflict of interest, financial or otherwise.

\section{ACKNOWLEDGEMENTS}

We thank all the patients, who gave their informed and written consent for this project.

\section{REFERENCES}

[1] Dadoun S, Zeboulon-Ktorza N, Combescure C, et al. Mortality in rheumatoid arthritis over the last fifty years: Systematic review and meta-analysis. Joint Bone Spine 2013; 80(1): 29-33 [http://dx.doi.org/10.1016/j.jbspin.2012.02.005] [PMID: 22459416]

[2] Ogdie A, Maliha S, Shin D, et al. Cause-specific mortality in patients with psoriatic arthritis and rheumatoid arthritis. Rheumatology (Oxford) 2017; 56(6): 907-11.

[http://dx.doi.org/10.1093/rheumatology/kew502] [PMID: 28158384]

[3] Gabriel SE, Michaud K. Epidemiological studies in incidence, prevalence, mortality, and comorbidity of the rheumatic diseases. Arthritis Res Ther 2009; 11(3): 229.

[http://dx.doi.org/10.1186/ar2669] [PMID: 19519924]

[4] Bech B, Primdahl J, van Tubergen A, Voshaar M, Zangi HA, Barbosa L, et al. 2018 update of the EULAR recommendations for the role of the nurse in the management of chronic inflammatory arthritis. Ann Rheum Dis 2019; 0: 1-8.

[http://dx.doi.org/10.1136/annrheumdis-2019-215458] [PMID: 31300458]

[5] Dougados M, Soubrier M, Antunez A, et al. Prevalence of comorbidities in rheumatoid arthritis and evaluation of their monitoring: Results of an international, cross-sectional study (COMORA). Ann Rheum Dis 2014; 73(1): 62-8.

[http://dx.doi.org/10.1136/annrheumdis-2013-204223] [PMID 24095940]

6] El-Zorkany B, Mokbel A, Gamal SM, Mousa M, Youssef M, Hmamouchi I. Comparison of comorbidities of the Egyptian rheumatoid arthritis patients to the global cohort of the COMORA study: a post-hoc analysis. Clin Rheumatol 2016; 35(5): 1153-9. [http://dx.doi.org/10.1007/s10067-015-3142-4] [PMID: 26670453]

[7] Choi IA, Park SH, Cha H-S, et al. Prevalence of co-morbidities and evaluation of their monitoring in Korean patients with rheumatoid arthritis: Comparison with the results of an international, crosssectional study (COMORA). Int J Rheum Dis 2018; 21(7): 1414-22. [http://dx.doi.org/10.1111/1756-185X.13013] [PMID: 28261976]

[8] Balsa A, Lojo-Oliveira L, Alperi-López M, et al. Prevalence of comorbidities in rheumatoid arthritis and evaluation of their monitoring in clinical practice: The spanish cohort of the COMORA study. Reumatol Clin 2019; 15(2): 102-8.

[http://dx.doi.org/10.1016/j.reuma.2017.06.002] [PMID: 28711461]

[9] Emery P, Sebba A, Huizinga TWJ. Biologic and oral diseasemodifying antirheumatic drug monotherapy in rheumatoid arthritis. Ann Rheum Dis 2013; 72(12): 1897-904.

[http://dx.doi.org/10.1136/annrheumdis-2013-203485] [PMID 23918035]

[10] Statistik Austria. Österreichische Gesundheitsbefragung 2014.http://www.statistik.at/web_de/services/publikationen/4/index.ht $\mathrm{ml}$ ?includePage $=$ detailedView\&sectionName $=$ Gesundheit\&pubId $=71$

[11] Boyer J-F, Gourraud P-A, Cantagrel A, Davignon J-L, Constantin A Traditional cardiovascular risk factors in rheumatoid arthritis: A metaanalysis. Joint Bone Spine 2011; 78(2): 179-83. [http://dx.doi.org/10.1016/j.jbspin.2010.07.016] [PMID: 20851020]

[12] Daïen CI, Tubery A, Beurai-Weber M, et al. Relevance and feasibility of a systematic screening of multimorbidities in patients with chronic inflammatory rheumatic diseases. Joint Bone Spine 2019; 86(1): 49-54.

[http://dx.doi.org/10.1016/j.jbspin.2018.03.016] [PMID: 29654949]

[13] Mattey DL, Brownfield A, Dawes PT. Relationship between pack-yea history of smoking and response to tumor necrosis factor antagonists in patients with rheumatoid arthritis. J Rheumatol 2009; 36(6): 1180-7. [http://dx.doi.org/10.3899/jrheum.081096] [PMID: 19447930]

[14] Söderlin MK, Petersson IF, Geborek P. The effect of smoking on response and drug survival in rheumatoid arthritis patients treated with their first anti-TNF drug. Scand J Rheumatol 2012; 41(1): 1-9. [http://dx.doi.org/10.3109/03009742.2011.599073] [PMID: 22118371]

[15] Hyrich KL, Watson KD, Silman AJ, Symmons DPM. British Society for Rheumatology Biologics Register. Predictors of response to antiTNF-alpha therapy among patients with rheumatoid arthritis: results from the British Society for Rheumatology Biologics Register. Rheumatology (Oxford) 2006; 45(12): 1558-65.

[http://dx.doi.org/10.1093/rheumatology/kel149] [PMID: 16705046]

[16] Gabriel SE, Crowson CS. Risk factors for cardiovascular disease in rheumatoid arthritis. Curr Opin Rheumatol 2012; 24(2): 171-6. [http://dx.doi.org/10.1097/BOR.0b013e32834ff2fd] [PMID: 22249350]

17] Stavropoulos-Kalinoglou A, Metsios GS, Panoulas VF, et al. Associations of obesity with modifiable risk factors for the development of cardiovascular disease in patients with rheumatoid arthritis. Ann Rheum Dis 2009; 68(2): 242-5.

[http://dx.doi.org/10.1136/ard.2008.095596] [PMID: 18677010]

[18] Solomon DH, Kremer J, Curtis JR, et al. Explaining the cardiovascular risk associated with rheumatoid arthritis: Traditional risk factors versus markers of rheumatoid arthritis severity. Ann Rheum Dis 2010; 69(11): $1920-5$

[http://dx.doi.org/10.1136/ard.2009.122226] [PMID: 20444756]

[19] Naranjo A, Sokka T, Descalzo MA, et al. QUEST-RA Group. Cardiovascular disease in patients with rheumatoid arthritis: Results from the QUEST-RA study. Arthritis Res Ther 2008; 10(2): R30. [http://dx.doi.org/10.1186/ar2383] [PMID: 18325087]

[20] Kanis JA, Borgström F, Compston J, et al. SCOPE: A scorecard for osteoporosis in Europe. Arch Osteoporos 2013; 8: 144 [http://dx.doi.org/10.1007/s11657-013-0144-1] [PMID: 24030479]

(C) 2019 Levytskyi et al.

This is an open access article distributed under the terms of the Creative Commons Attribution 4.0 International Public License (CC-BY 4.0), a copy of which is available at: (https://creativecommons.org/licenses/by/4.0/legalcode). This license permits unrestricted use, distribution, and reproduction in any medium, provided the original author and source are credited. 